\title{
Utilização de massas cerâmicas na produção de agregado sintético de argila calcinada para uso em concreto
}

\section{(Use of ceramic bodies in the production of synthetic aggregate calcined clay for use in concrete)}

\author{
E. M. Cabral, R.J. de Sá, R. K. Vieira, R. P. Vasconcelos \\ Laboratório de Ensaios de Materiais - LEM, Universidade Federal do Amazonas - UFAM \\ Av. Gen. Rodrigo Otávio Jordão 3000, Manaus, AM \\ edisley_cabral@yahoo.com.br,vasconcelos@ufam.edu.br
}

\begin{abstract}
Resumo
A região amazônica, pela sua formação geológica, não dispõe de rochas de fácil acesso para uso na construção civil; devido a isto, o seixo rolado é obtido da dragagem do leito dos rios, sendo o agregado graúdo comercialmente mais utilizado para a produção de concreto. Neste trabalho é apresentado um estudo das características e propriedades tecnológicas de duas massas cerâmicas utilizadas para produção de tijolo, oriundas das cidades de Iranduba e Manacapuru, AM, com a finalidade de se fabricar agregado sintético de argila calcinada para uso em concreto. As massas cerâmicas foram submetidas a ensaios de difração de raios X, determinação de composição química e de distribuição do tamanho das partículas, e plasticidade. Foram confeccionados corpos-de-prova por prensagem uniaxial a $20 \mathrm{MPa}$ para a queima nas temperaturas de $850,950,1050,1150{ }^{\circ} \mathrm{C}$, sendo as propriedades tecnológicas após queima avaliadas por retração linear, absorção de água, massa específica aparente, massa unitária e temperatura de gresificação. A massa cerâmica que apresentou menor massa específica aparente e o menor percentual de umidade de moldagem foi escolhida como matéria-prima para a fabricação do agregado sintético de argila calcinada. Esse agregado foi usado em substituição ao agregado natural da região amazônica, o seixo rolado, em concreto estrutural.
\end{abstract}

Palavras-chave: massa cerâmica, argila calcinada, gresificação.

\begin{abstract}
The amazonic region is geologically mainly composed by sedimentary rocks; by consequence, it is difficult to obtain igneous rocks to use in concrete. Hence, the natural gravel produced by the weathering action of running water on the beds and banks of streams is largely used. Nowadays, the substitution of natural gravel by an aggregate whose production minimizes the environmental impact has been a theme of research. This work presents a study of the characteristics and technological properties of two ceramic pastes from Iranduba and Manacapuru. AM, with the purpose of manufacturing synthetic aggregate of calcined clay for use in concrete. The ceramic pastes were analyzed by X-ray diffraction, evaluation of chemical composition, particle size distribution and plasticity. The samples were prepared by uniaxial pressing at $20 \mathrm{MPa}$ and calcined at $850,950,1050$ and $1150^{\circ} \mathrm{C}$. The technological properties evaluated were: linear shrinkage, water absorption, apparent specific mass and vitrification temperature. The ceramic paste that presented the smallest apparent specific mass and smallest percentile of molding humidity was chosen for synthetic aggregate. The results obtained for the concrete produced with the synthetic aggregate of calcined clay show its potential as a substitute of the natural aggregate of the Amazonic region, the natural gravel.
\end{abstract}

Keywords: ceramic body, calcined clay, vitrification.

\section{INTRODUÇÃO}

A fabricação de cerâmica vermelha nos municípios de Iranduba e Manacapuru, estado do Amazonas, constitui um setor de destaque na economia local. Essas indústrias encontram-se localizadas numa região onde os depósitos argilosos recobrem a formação do Alter-do-chão, que são utilizados como matéria-prima. Nestes dois municípios existem vinte e seis indústrias oleiras em funcionamento, sendo que apenas duas olarias fabricam telhas e as restantes produzem tijolos cerâmicos furados (geralmente de oito furos) e maciços, estes últimos sob encomenda [1].

Por outro lado, Manaus, capital do estado do Amazonas, consome cerca de $600.000 \mathrm{~m}^{3}$ de agregado graúdo anualmente, sendo a metade desse total adquirido pelas centrais dosadoras locais [2]. Desse quantitativo, cerca de $90 \%$ é de agregado na forma de seixo rolado. As pedreiras de rocha sã localizam-se longe do maior centro consumidor, como é o caso do município de Presidente Figueiredo que se encontra a aproximadamente $130 \mathrm{~km}$ de Manaus, e por 
causa disto a opção é quase sempre o emprego de seixo rolado, extraído do fundo dos rios.

Grande parte dos maciços da região Amazônica foi formada no interior de uma bacia intracratônica, gerando sedimentos inconsolidados de pequena textura, tais como areia, silte e argila. Desta forma, as principais capitais amazônicas, Manaus, Belém e Rio Branco, bem como mais da metade da área do estado do Amazonas, não são cobertas por rochas. Destaca-se, nestas áreas o uso de agregados naturais (seixo rolado ou pedra britada), para serem empregados na construção civil.

O uso de argila calcinada como agregado sintético, além de promover uma alternativa para as obras civis, está relacionado com a diminuição do impacto ambiental causado no leito dos rios, provocado pela extração predatória do seixo rolado, que causa assoreamento de suas margens. Entende-se por agregado artificial de argila, aquele proveniente da transformação de um solo ou folhelho argiloso previamente processado, em um material inerte e com resistência mecânica satisfatória para uma determinada finalidade. Essas características são normalmente obtidas através do aquecimento da matéria-prima (solo ou folhelho) em elevadas temperaturas. A qualidade do produto acabado depende fundamentalmente da matéria-prima utilizada, da temperatura de queima e do processo de conformação da massa cerâmica como normalmente são chamados os solos argilosos destorroados, misturados, umedecidos, laminados que são à base do processo cerâmico [3]. Os agregados leves produzidos a partir de argilas ou folhelhos podem ser divididos em duas classes: agregados leves (expandidos ou sinterizados) e agregados calcinados.

A argila expandida é o produto obtido pelo aquecimento de argila ou folhelhos argilosos na temperatura em torno de $1200{ }^{\circ} \mathrm{C}$. Próximo desta temperatura, uma parte dos constituintes do material se funde gerando uma massa viscosa, enquanto a outra parte se decompõe quimicamente liberando gases que são incorporados por esta massa sinterizada que é expandida. Esses gases, retidos no interior do agregado de argila, não podem escapar para seu exterior devido à fase liquida, proporcionada pelos elementos fundentes, que envolve a partícula. A estrutura celular, ou seja, os vazios internos estão isolados entre si por paredes impermeáveis, que se mantém após o resfriamento, de modo que a massa específica do agregado resultante torna-se menor do que antes do aquecimento, podendo ser utilizado como agregado graúdo na fabricação de concretos leves, com o objetivo de reduzir o peso próprio das estruturas [3-5].

$\mathrm{O}$ agregado de argila expandida pode ser produzido a partir do aquecimento da matéria-prima, triturada, ou moída e pelotizada, feito geralmente, em forno rotativo. Pode também ser obtido por sinterização contínua. Nesse caso, o material bem umedecido é transportado numa esteira, sob queimadores, de modo que o calor atinge gradualmente toda a espessura da camada [3-6].

Agregados sintéticos fabricados pela queima de argila a partir de $760{ }^{\circ} \mathrm{C}$ oferecem possibilidades bastante interessantes para o uso rodoviário, pois ensaios experimentais mostram que a argila queimada nesta temperatura se desidroxila, podendo fornecer agregados estáveis e aptos para serem usados em condições mais econômicas que o agregado sintético de argila expandida. De acordo com estas experiências, observa-se que praticamente qualquer argila que, depois de molhada e moldada em forma de pelotas, venha a formar grãos duros e secos ao ar, pode servir para a fabricação de agregados de "argila queimada" [4].

Os concretos produzidos com agregados originários de rochas têm massa específica variando entre $2200 \mathrm{~kg} / \mathrm{m}^{3}$ e $2600 \mathrm{~kg} / \mathrm{m}^{3}$. Concreto com menor massa específica pode resultar em vantagens significativas quanto a elementos estruturais com menor seção transversal e uma correspondente redução das dimensões da fundação. Outra característica importante a ser observada no agregado leve é a boa aderência entre este e a pasta hidratada de cimento que o envolve. Esta aderência ocorre pela textura áspera da superfície do agregado, resultando em um intertravamento mecânico entre o agregado e a pasta [7-8].

Levando-se em consideração diversas experiências com argila calcinada no meio científico, este trabalho apresenta um estudo das características dos solos argilosos proveniente do pólo oleiro de Iranduba e Manacapuru no estado do Amazonas e a utilização destas matérias-primas na fabricação de agregados sintéticos para uso em concreto estrutural, através de ensaios químicos, físicos, mecânicos.

\section{MATERIAIS E MÉTODOS}

A coleta de amostras deformadas de argila in natura deuse na região do município Manacapuru, estado do Amazonas, em jazidas usadas pelas olarias. A partir da coleta de argila usada para fabricação de tijolos de duas olarias, estas foram identificas como solo 1 (Iranduba) e solo 2 (Manacapuru). A caracterização das amostras de argila teve o objetivo de conhecer o comportamento físico, químico e mineralógico, de tal forma que se pudesse prever sua melhor utilização. No laboratório, as amostras de argila foram então postas para secar à sombra para retirar a umidade em excesso. Em seguida, foram destorroadas e submetidas aos ensaios de caracterização física, química, mineralógica e ensaios tecnológicos. Estes ensaios compreendem a determinação da granulometria do material argiloso e os limites de consistência: de liquidez [9] e de plasticidade [10].

A composição química foi determinada por espectrometria de fluorescência de raiosX por meio de energia dispersiva (Shimadzu modelo EDX700HS), sendo quantificados os elementos químicos. As análises mineralógicas foram efetuadas no laboratório de difração de raios $\mathrm{X}$ do Departamento de Geociências do Instituto de Ciências Exatas da Universidade Federal do Amazonas. As amostras foram separadas granulometricamente em uma centrífuga, coletando-se a fração argila. As análises foram feitas na amostra total e na fração argila. Nas amostras onde ocorreram reflexões em ângulo $<10^{\circ}(2 \theta)$, que são indicativos da presença de argilominerais expansivos, a lâmina foi 
submetida a atmosfera de etileno-glicol, em um dessecador a vácuo, por um período de $12 \mathrm{~h}$, e, posteriormente, analisada no difratômetro Shimadzu, modelo XRD6000, com radiação $\mathrm{Cuk}_{\alpha}$, sendo identificadas as fases cristalinas.

Para os ensaios físicos, foram moldados corpos-de-prova prismáticos nas dimensões $60 \times 20 \times 10 \mathrm{~cm}^{3}$. Em seguida os corpos-de-prova foram queimados a 850, 950, 1050 e $1150{ }^{\circ} \mathrm{C}$, com $1 \mathrm{~h}$ de patamar. Nessas amostras foram realizados os ensaios de absorção de água e retração linear e massa específica aparente.

As argilas foram umedecidas com a adição de água, próximo ao limite de plasticidade e moldadas em um moinho adaptado, que na sua saída eram colocadas boquilhas retangulares com as dimensões variando de $4,8 \mathrm{~mm}$ a 12,5 mm, Fig. 1. Nas olarias são usados equipamentos com a finalidade de extrudar a matéria-prima, ou seja, conduzir o solo até a saída dos moldes dos tijolos, definindo assim a forma geométrica desejada.

Ressalte-se que os fornos do pólo oleiro de Iranduba e Manacapuru têm capacidade de queimar as matérias-primas utilizadas para produção de tijolos a 850 e $950{ }^{\circ} \mathrm{C}$. Desta forma, visando um futuro aproveitamento desse tipo de
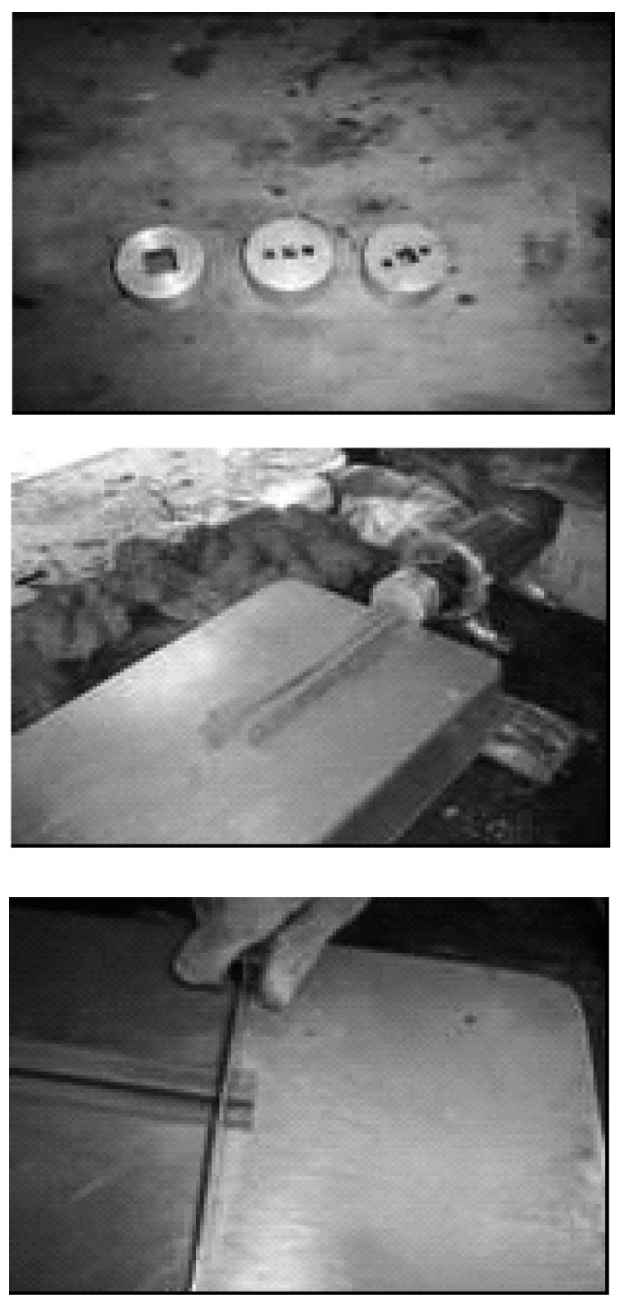

Figura 1: Moldagem dos agregados de argila. [Figure 1: Moulding of the clay aggregates.]

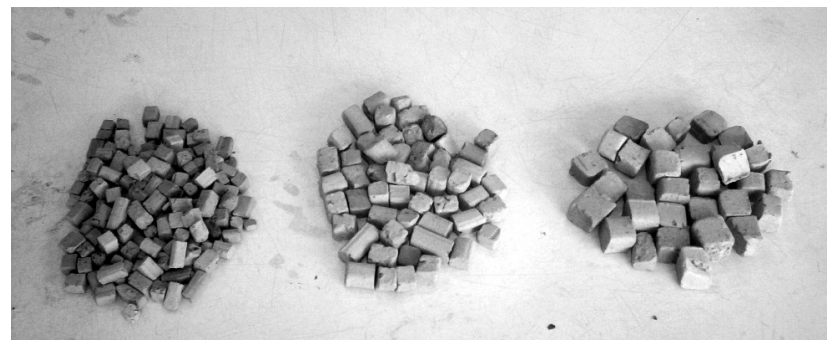

Figura 2: Agregado sintético de argila calcinada com diferentes dimensões.

[Figure 2: Synthetic aggregate of calcined clay with different dimension.]

forno para a produção do agregado sintético, fez-se uma verificação do comportamento proporcionado pela queima em $850{ }^{\circ} \mathrm{C}$, sendo os agregados de argila (Fig. 2) calcinados em um forno mufla, por $1 \mathrm{~h}$ após ter atingido a temperatura desejada.

Para a composição do traço, que é a proporção dos diversos constituintes do concreto, utilizou-se o cimento CP32-Z, o agregado sintético e areia de jazida. Fez-se então, uma análise de quatro traços diferentes, variando-se o consumo de cimento e a proporção de agregados na mistura. Para tanto, diversas dosagens, que são as misturas para cada traço, foram executadas, verificando-se a trabalhabilidade, ou seja, a facilidade de moldar o concreto fresco, através do ensaio de tronco de cone [11], medindo-se a partir da configuração inicial o deslocamento da superfície superior do tronco de cone de concreto fresco, valor conhecido como "slump". Definido cada traço, corpos-de-prova cilíndricos de concreto foram moldados, sendo estes levados a uma câmara úmida para a cura. Após 3, 7 e 28 dias, foram realizados ensaios de compressão simples para estabelecer a resistência à compressão de cada espécie.

\section{RESULTADOS E DISCUSSÃO}

Caracterização física e mineralógica das amostras de solo.

Na Tabela I são apresentados os resultados da caracterização física das amostras dos solos 1 e 2. Observase a elevada plasticidade do solo 1, que afeta diretamente a umidade de moldagem, sendo necessário adicionar maior quantidade de água para se obter uma massa trabalhável. Este teor de umidade indica que esta argila necessita de no mínimo $55 \%$ de água para ser conformada, afetando diretamente a etapa de secagem, que pode ser mais problemática com o aumento do risco de defeitos provocados pela retração ou o surgimento de trincas, e o prolongamento do tempo de secagem. Deve-se destacar que os valores razoáveis de umidade para extrudar uma massa cerâmica estão entre 22$24 \%$, quando se utiliza uma extrusora a vácuo [12].

O limite de liquidez (LL) é o teor de umidade que uma massa cerâmica começa a se comportar como um líquido e se relaciona com a água adsorvida associada à argila, correspondendo à máxima umidade que ainda permite a 
Tabela I - Caracterização das amostras de solo.

[Table I - Characterization of the soil samples.]

\begin{tabular}{ccccccc}
\hline Amostras & $\begin{array}{c}\text { Argila } \\
(\%)\end{array}$ & $\begin{array}{c}\text { Silte } \\
(\%)\end{array}$ & $\begin{array}{c}\text { Areia } \\
(\%)\end{array}$ & $\begin{array}{c}\text { Limite de } \\
\text { Plasticidade }(\%)\end{array}$ & $\begin{array}{c}\text { Limite de } \\
\text { Liquidez (\%) }\end{array}$ & $\begin{array}{c}\text { Índice de } \\
\text { Plasticidade (\%) }\end{array}$ \\
\hline Solo 1 & 43,96 & 50,27 & 5,77 & 55 & 86 & 31 \\
Solo 2 & 43,53 & 44,22 & 12,27 & 28 & 50 & 22 \\
\hline
\end{tabular}

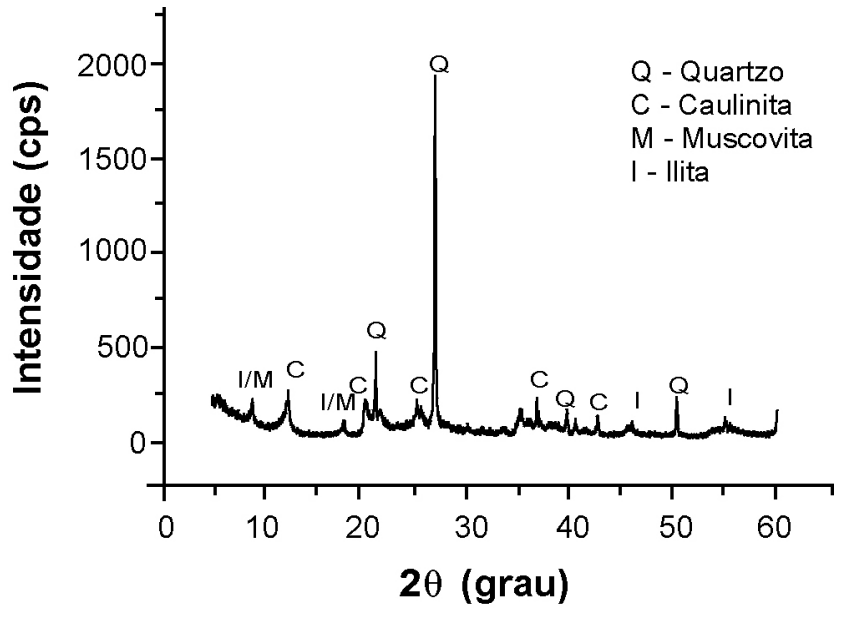

Figura 3: Difratograma de raios $\mathrm{X}$ do solo 1.

[Figure 3: X-ray diffraction pattern of the soil 1.]

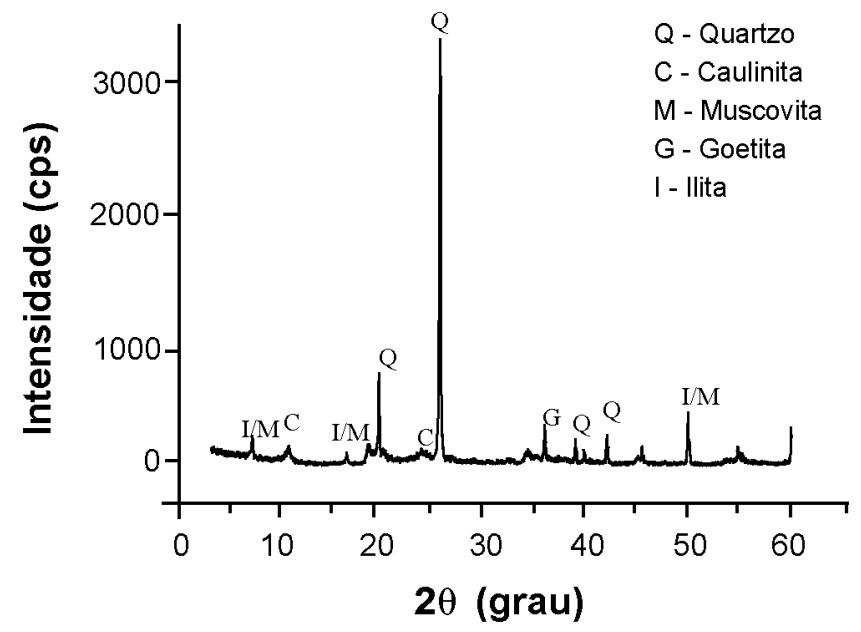

Figura 4: Difratograma de raios X do solo 2.

[Figure 4: X-ray diffraction pattern of the soil 2.]

sua moldagem. A massa cerâmica moldada com umidade em torno do (LL) produziu um agregado muito poroso, considerando que a excessiva quantidade de água é retirada durante a secagem, e os poros anteriormente ocupados por água ficavam vazios.

Quanto à plasticidade dos solos para a fabricação do agregado sintético de argila calcinada, poderão ser utilizadas argilas ou misturas argilosas que possuam índice de plasticidade (IP) superior a 15\% [4]. Este fato demonstra que a matéria-prima para a fabricação do agregado sintético precisa ter alta plasticidade. O menor IP encontrado nos solos estudados é $22 \%$, portanto acima do limite estabelecido anteriormente.

Com relação à granulometria, observa-se que o teor de argila é praticamente o mesmo, em ambos os solos estudados, no entanto, os teores de silte e areia são diferentes. O menor teor de areia encontrado no solo 1 certamente contribuiu para o maior valor de plasticidade obtido neste solo em relação ao solo 2 . O solo 2 apresentou menor limite de plasticidade, tendo em vista que esse parâmetro indica o teor de umidade mínimo para que a uma argila ainda possa ser conformada minimizando-se os riscos de fissuras nas peças cerâmicas. Desta forma, a massa cerâmica conformada no LP apresentou porosidade inferior ao obtido quando utilizado o LL.

Nos resultados obtidos da difração de raios X, Figs. 3 e 4, observa-se a presença da caulinita e de quartzo. Em nenhum dos solos foram encontrados argilominerais expansivos como a montmorilonita. No entanto, há picos de difração característicos de ilita, a qual pertence ao grupo dos minerais encontrados em argila e que apresenta essencialmente a estrutura da muscovita, sendo menos expansiva que a montmorilonita. Nesses dois solos a incidência de picos característicos de caulinita é maior. A baixa plasticidade encontrada no solo 2 deve-se ao fato de que há um elevado percentual de minerais não-plásticos como mica muscovita e a goetita.

\section{Composição química e sinterização das amostras de solo}

Na Tabela II observa-se que o solo 1 apresenta maior teor de alumina, que é um indicativo da existência do maior percentual de minerais argilosos. Este percentual justifica os elevados índices de consistência encontrados para este solo. Também pode-se observar nesses dois solos a ocorrência de um teor superior a 5\% de óxido de ferro, responsável pela cor avermelhada das peças cerâmicas antes e após a queima. Já os teores de sílica, alumínio e ferro são característicos das massas usadas na produção de cerâmica vermelha, o que corrobora o uso industrial desse tipo de solo, sendo assim viabilizado a fabricação do agregado sintético, pois este nada mais é que um produto da cerâmica vermelha.

A gresificação de massas cerâmicas é a medida da evolução da microestrutura do material durante a queima. A curva de gresificação utilizada em revestimentos cerâmicos 
Tabela II - Composição das amostras.

[Table II - Chemical composition of the samples.]

\begin{tabular}{ccccccccccc}
\hline Amostras & $\mathrm{SiO}_{2}$ & $\mathrm{Fe}_{2} \mathrm{O}_{3}$ & $\mathrm{Al}_{2} \mathrm{O}_{3}$ & $\mathrm{MgO}$ & $\mathrm{CaO}$ & $\mathrm{TiO}_{2}$ & $\mathrm{Na}_{2} \mathrm{O}$ & $\mathrm{K}_{2} \mathrm{O}$ & $\mathrm{MnO}$ & $\mathrm{PF}$ \\
\hline Solo 1 & 66,0 & 6,2 & 16,11 & 1,5 & 1,1 & 0,9 & 1,4 & 2,0 & 0,1 & 4,7 \\
Solo 2 & 59,56 & 7,3 & 14,55 & 1,21 & 0,92 & 1,2 & 1,5 & 2,19 & 0,11 & 11,42 \\
\hline
\end{tabular}

PF: perda ao fogo.

ilustra o comportamento térmico do material em função da temperatura [13]. Estas curvas apresentam as variações de absorção de água (AA) e retração linear (RL) em função da temperatura de queima. Esse tipo de curva indica a temperatura onde o material começa a gresificar, correspondendo ao ponto de interseção entre a curva de absorção e retração. O ponto de interseção é chamado "ponto de grés", sendo este o ponto de início da gresificação do material, dado por reações químicas entre as interfaces dos grãos, onde ocorre gradativamente a união

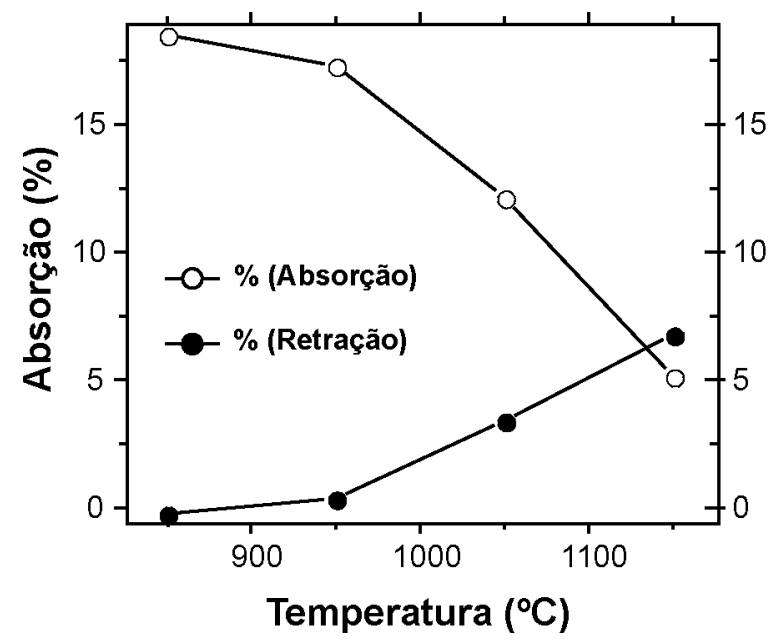

Figura 5: Curva de gresificação do solo 1.

[Figure 5: Vitrification curves of soil 1.]

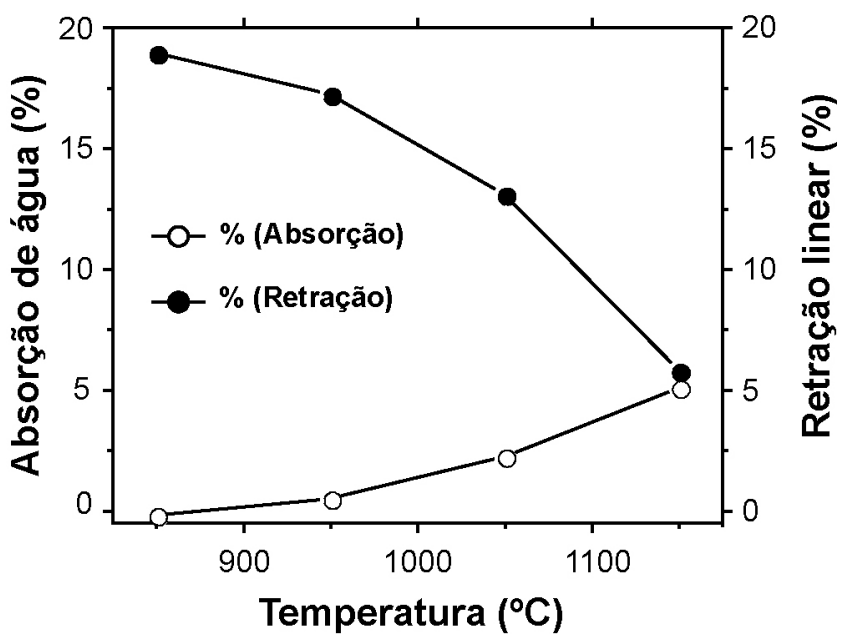

Figura 6: Curva de gresificação do solo 2.

[Figure 6: Vitrification curve of soil 2.]

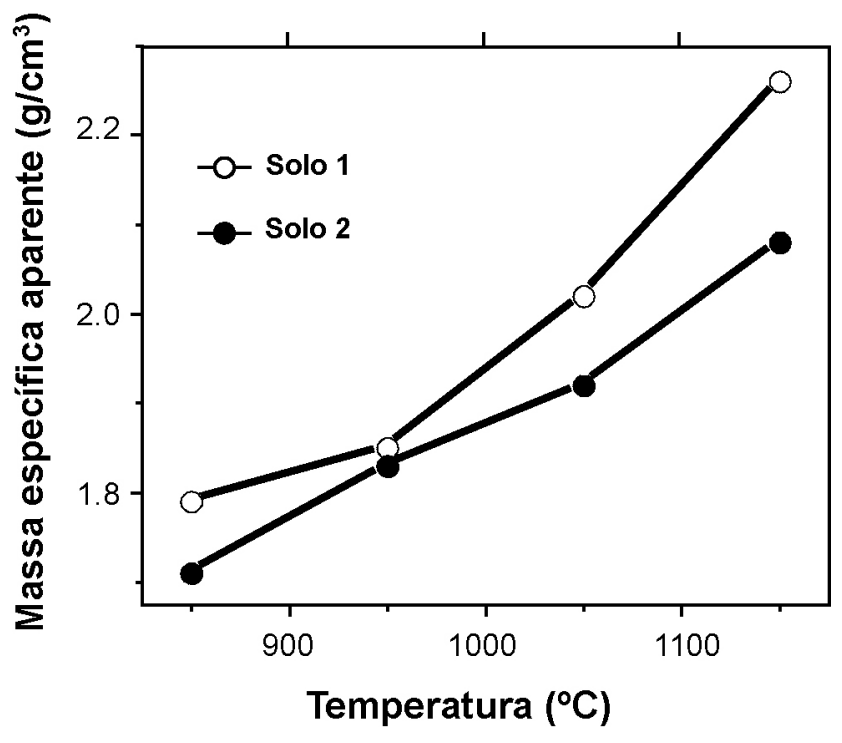

Figura 7: Massa específica aparente versus temperatura.

[Figure 7: Apparent specific mass as a function of the temperature.]

de dois grãos tornando-se um só. Conforme as Figs. 5 e 6, os solos 1 e 2 começam a gresificar a partir de $1125^{\circ} \mathrm{C}$. De $850^{\circ} \mathrm{C}$ até $950^{\circ} \mathrm{C}$ é observada pouca variação no percentual de absorção de água e uma certa estabilidade dimencional das peças devida baixa retração linear. Já a partir de $1000{ }^{\circ} \mathrm{C}$ ocorre um aumento da retração passando de um pouco mais de $1 \%$ e chegando a próximo de $7 \%$, indicando um aumento da quantidade de fase líquida, oriunda da reação dos elementos fundentes, reduzindo a absorção de água de $15 \%$ para menos de $6 \%$.

Na Fig. 7 são apresentados os resultados da massa específicaaparente doscorpos-de-provaqueimados.Observase que até $950^{\circ} \mathrm{C}$ a densificação dos solos 1 e 2 é inferior a 2 $\mathrm{g} / \mathrm{cm}^{3}$ e em $1150{ }^{\circ} \mathrm{C}$ a massa específica atinge os valores de 2,26 e $2,08 \mathrm{~g} / \mathrm{cm}^{3}$, respectivamente. O solo 1 apresenta teor de fundente $\left(\mathrm{Fe}_{2} \mathrm{O}_{3}+\mathrm{MgO}+\mathrm{CaO}+\mathrm{Na}_{2} \mathrm{O}+\mathrm{K}_{2} \mathrm{O}\right)$ em torno de $12,20 \%$ enquanto no solo 2 é da ordem de $13,12 \%$ que, em tese, significaria que este último deveria ser mais denso. Por outro lado, considerando que a densificação está diretamente ligada a redução da porosidade, uma elevada perda ao fogo de 11,4\% contribui de forma significativa para elevar a porosidade e desse modo reduzir a densificação. O solo 1 apresenta elevada plasticidade, comprovando a existência de argilas de granulometria muito fina que na moldagem elevam o grau de compactação (empacotamento) a verde, 
resultando dessa forma em peças cerâmicas mais densas. O solo 2 apresentou a menor massa específica aparente e o menor teor de umidade de moldagem, por isso foi utilizado como matéria-prima para a produção agregado graúdo de argila calcinada a $850^{\circ} \mathrm{C}$. A escolha desta temperatura fez-se em decorrência dos fornos da região atingirem temperatura que variam de $850{ }^{\circ} \mathrm{C}$ a $950{ }^{\circ} \mathrm{C}$. Deve-se salientar que esses agregados foram calcinados em forno mufla por um período de $1 \mathrm{~h}$ após atingir a temperatura estabelecida.

\section{Dosagens do agregado sintético de argila calcinada em traços de concreto}

Para a aplicação dos agregados sintéticos de argila calcinada em concreto foram obtidos através de ensaios os parâmetros físicos seguintes: a massa unitária pelo método da caixa [7] foi igual a $1,08 \mathrm{~kg} / \mathrm{dm}^{3}$; a massa específica aparente [15] foi igual a $1,73 \mathrm{~g} / \mathrm{cm}^{3}$; a absorção de água [15] foi igual a $18,90 \%$.

Para a dosagem experimental saturou-se o agregado por 24 h, deixando sua superfície lisa, pois sua elevada absorção de água superior a $18 \%$, retirava a água de amassamento do concreto. Essa elevada porosidade diminui a resistência do concreto, porém, o aspecto positivo é uma eficiente cura interna, reduzindo as fissuras, a retração e a dissipação do calor de hidratação. A este aspecto positivo uni-se ao fato de ser um agregado mais leve que o agregado rochoso, produzindo-se um concreto de massa específica igual 2,06 $\mathrm{kg} / \mathrm{dm}^{3}$, menor do que a de um concreto convencional que atinge $2,5 \mathrm{~kg} / \mathrm{dm}^{3}$. O agregado convencional empregado, o seixo rolado, apresenta dimensão máxima de $19 \mathrm{~mm}$ com mais de $37 \%$ de material inferior a $4,8 \mathrm{~mm}$. O agregado sintético de argila calcinada, por outro lado, foi fabricado com a dimensão máxima de $12,5 \mathrm{~mm}$ para que fosse possível obter um comportamento semelhante ao do agregado convencional, e sua dimensão inferior de $4,8 \mathrm{~mm}$ foi estabelecida devido à restrição dos moldes de produção. Deve-se salientar que o seixo rolado apresenta um grande percentual de finos, enquanto que o agregado sintético apresentou o menor índice de vazios quando misturado com um percentual de $55 \%, 20 \%$ e $25 \%$ dos agregados nas dimensões de $4,8 \mathrm{~mm}$, $9,5 \mathrm{~mm}$ e $12,5 \mathrm{~mm}$, respectivamente.

$\mathrm{Na}$ Tabela III verifica-se que o consumo de cimento foi decrescendo e sua resistência à compressão também

Tabela III - Resultado das dosagens com argila calcinada. [Table III - Result of the dosages with calcined clay.]

\begin{tabular}{cccccc}
\hline Traço & $\begin{array}{c}\text { Slump } \\
(\mathrm{cm})\end{array}$ & $\begin{array}{c}\text { Consumo } \\
\text { de cimento } \\
\left(\mathrm{kg} / \mathrm{m}^{3}\right)\end{array}$ & 3 dias & 7 dias & $\begin{array}{c}\text { Resistência a compressão } \\
\text { dias }\end{array}$ \\
\hline 1 & 12 & 388 & 19,30 & 22,10 & 28,85 \\
2 & 6 & 368 & 16,61 & 19,10 & 27,95 \\
3 & 4 & 349 & 15,88 & 20,70 & 27,94 \\
\hline
\end{tabular}

foi reduzida. A norma NBR 6118 [16] recomenda que a resistência a compressão aos 28 dias para concreto estrutural não seja inferior a $20 \mathrm{MPa}$. No entanto, as dosagens realizadas neste trabalho atingiram valores próximos ou superiores ao limite estabelecido aos sete dias de cura, sendo que aos 28 dias a resistência obtida foi superior a $27 \mathrm{MPa}$, mesmo reduzindo o consumo de cimento para $349 \mathrm{~kg} / \mathrm{m}^{3}$. No decorrer das dosagens foi observado que o concreto apresentava um comportamento com melhor trabalhabilidade, quando seu teor de argamassa era igual ou superior a $57 \%$.

\section{CONCLUSÕES}

Os solos estudados apresentam composição mineralógica semelhante e a composição química distinguese no percentual de sílica e na quantidade de alumina. Os limites de consistência demonstram que o solo 1 apresenta elevado percentual de fração argila, com a predominância de argilominerais cauliniticos. O solo 2 apresenta baixa plasticidade, que proporcionará uma massa cerâmica com menor quantidade de água na sua conformação. Isso reflete diretamente no tempo de secagem e na redução dos defeitos provocados pela retração.

No comportamento de queima, os solos apresentaram valores de absorção elevados até $1000^{\circ} \mathrm{C}$ e certa estabilidade dimensional com pequenas contrações volumétricas. Isso comprova que os produtos cerâmicos oriundos do pólo oleiro de Iranduba e Manacapuru, AM, merecem um pouco mais de atenção quanto à porosidade. Já a temperatura de gresificação dos solos foi observada seu inicio próximo de $1125^{\circ} \mathrm{C}$.

$\mathrm{O}$ agregado fabricado com a argila de menor plasticidade, ainda apresentou elevada absorção de água, superior a $18 \%$, que retirava a água de hidratação do cimento e desta forma, modificava a relação água/cimento comprometendo a resistência mecânica do concreto. Por isso, optou-se pela saturação do agregado por $24 \mathrm{~h}$.

Com os resultados obtidos das dosagens, observa-se que o agregado sintético de argila calcinada, apresenta-se como uma promissora alternativa de substituição do seixo rolado na produção de concreto, tendo em vista que os resultados em termos de resistência a compressão em corpos-de-prova superam os $20 \mathrm{MPa}$ exigidos pela NBR 6118 (2003) [16].

\section{AGRADECIMENTOS}

À FAPEAM pelo auxilio para a realização deste trabalho. Ao Laboratório de Pavimentação da Universidade Federal do Amazonas, Prof. Nilton de Souza Campelo, ao CDEAM, ao Laboratório de Saneamento da Universidade Federal do Amazonas e ao Laboratório de Geoquímica da Universidade Federal do Amazonas.

\section{REFERÊNCIAS}

[1] N. S. Campelo, M. R. Morais, A. F. Aragão, E. M. Cabral, E. P. Rebelo, S. C. Pinheiro, O. A. Paiva, Cerâmica 
Industrial 11 (2006) 44.

[2] A. A. Bacellar, "Competitividade da alvenaria estrutural na cidade de Manaus", Dissertação de Mestrado, CPG/FT/ UFAM, Manaus, AM (2001) 87.

[3] P. S. Santos, Tecnologia de Argilas. $1^{\text {a }}$ Ed., Vol. 2, Editora Edgarg Blücher, SP (1975) 440.

[4] G. L. L. Cabral, "Metodologia de produção e emprego de agregados de argila calcinada para pavimentação", Dissertação de Mestrado, IME, Rio de Janeiro, RJ (2005) 110.

[5] A. Short, W. Kinniburgh, Lightweight concrete, $1^{\text {st }}$ Ed., C. R. Books, Londres, Inglaterra (1963) 511.

[6] W. G. Moravia, C. A. S. Oliveira, A. G. Gumieri, W. L Vasconcelos, Cerâmica 52 (2006) 193.

[7] A. M. Neville, Propriedades do Concreto, Ed. PINI, S. Paulo, SP (1997) 674.

[8] M. H. Zhang, O. E. Gjorv, Cement Concrete Res. 22 (1992) 47.

[9] ABNT-Associação Brasileira de Normas Técnicas, "Determinação do limite de liquidez", NBR-6459, Rio de Janeiro, RJ (1984).
[10] ABNT-Associação Brasileira de Normas Técnicas, "Determinação do limite de plasticidade", NBR-7180, Rio de Janeiro, RJ (1984).

[11] ABNT-Associação Brasileira de Normas Técnicas, "Determinação da consistência pelo abatimento do tronco de cone", NBR-7251, Rio de Janeiro, RJ (1982).

[12] C. M. F. Vieira, T. M. Soares, S. N. Monteiro, Cerâmica 49 (2003) 245.

[13] L. Sánchez-Muñoz, S. da S. Cava, C. A. Paskocimas, E. Cerisuelo, E. Longo, J. B. Carda, Cerâmica 48 (2002) 308.

[14] ABNT-Associação Brasileira de Normas Técnicas, "Determinação da massa unitária", NBR-7251, Rio de Janeiro, RJ (1982).

[15] ABNT-Associação Brasileira de Normas Técnicas, "Determinação da absorção e da massa específica de agregado graúdo", NBR-9937, Rio de Janeiro, RJ (1987).

[16] ABNT-Associação Brasileira de Normas Técnicas, "Projeto de estruturas de concreto", NBR-6118, Rio de Janeiro, RJ (2003).

(Rec. 17/11/2007, Rev. 18/02/2008, 16/04/2008, Ac. $17 / 04 / 2008)$ 